\title{
Herbert Becela verstorben
}

Georg Zizka

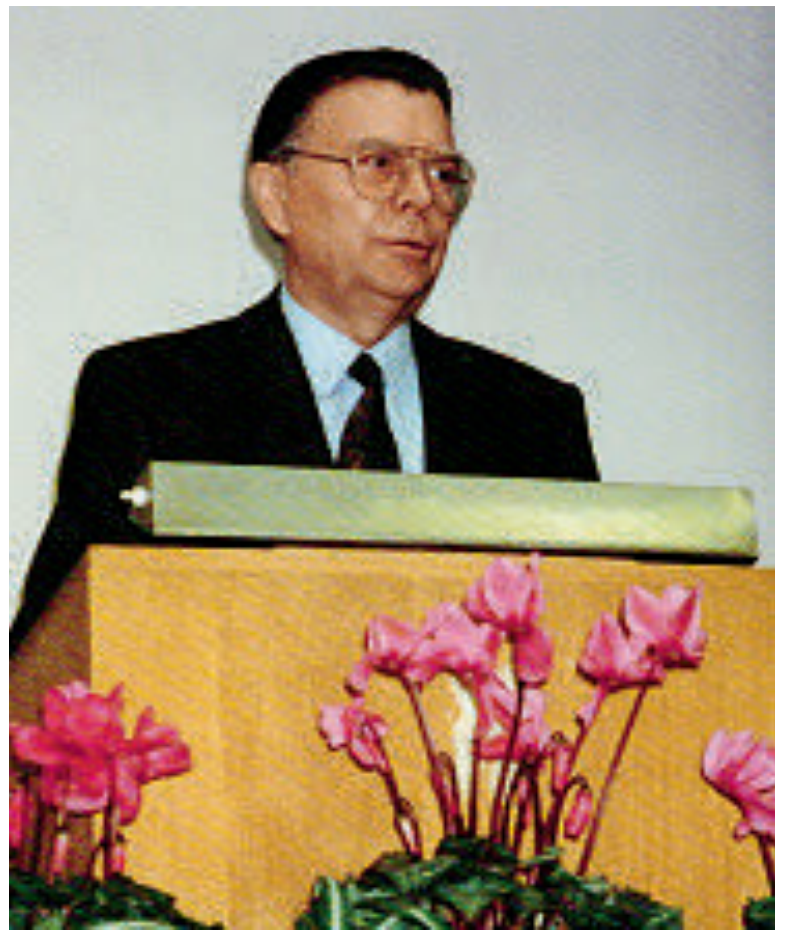

Offizielle Verabschiedung von Herbert Becela im Botanischen Institut am 30. Oktober 1992

Mehr als 30 Jahre lang - von 1961 bis 1992 war Herbert Becela Technischer Leiter des Botanischen Gartens der Goethe-Universität Frankfurt am Main. In die Zeit kurz vor seiner Einstellung fielen Neubau und Bezug der Biologischen Institute am Ende der Siesmayerstraße. Die Fertigstellung des von seinem Vorgänger Kurt Kiehne unter den aufeinander folgenden Garten-Direktoren und BotanikProfessoren Peter Stark, Fritz Overbeck (vertretungsweise), Friedrich Laibach und Camill Montfort gestalteten „neuen“ Botanischen Gartens war zur Zeit von Becelas Dienstantritt 1958 noch nicht abgeschlossen, ebenso wie der Umzug des Gartens von dem benachbart gelegenen sehr viel kleineren Areal des „alten“ Gartens auf dem heutigen Gelände des Palmengartens. In einer mehrjährigen Übergangszeit wurden noch Gewächshäuser und Büro im alten Botanischen Garten weiter- genutzt, obwohl das Gelände schon dem Palmengarten zugeschlagen war (heute befinden sich an dieser Stelle die Sukkulentensammlung des Tropicariums, die nördlich anschließende Botanische Sammlung, der Sommer-Sukkulentengarten, die „Alte Eibe“ und der Große Spielplatz).

Der nördlichste Teil des alten Gartens wurde Bestandteil des nun über 7 ha großen „neuen“ Botanischen Gartens. Auf diesem Gelände entstanden zu Anfang von Becelas Dienstzeit die Gewächshäuser, das Wirtschaftsgebäude des Botanischen Gartens und das Laborgebäude nach den Plänen des Universitätsbaudirektors Ferdinand Kramer. 1966, rechtzeitig zu der vom Botanischen Institut der Goethe-Universität ausgerichteten Tagung der Deutschen Botanischen Gesellschaft, waren dann diese letzten Bauarbeiten der Biologischen Institute fertiggestellt. Mit dem Umzug des Gartens war nicht nur eine erhebliche Flächenerweiterung, sondern auch die tiefgreifende Neugestaltung verbunden, die aktuelle Forschungsrichtungen aufgriff und komplementär zum benachbarten Palmengarten konzipiert war. Der Schwerpunkt lag auf den Freilandanlagen und der möglichst naturnahen Nachbildung von einheimischen Pflanzengemeinschaften, z. B. Buchenwald oder Glatthaferwiese. In die ersten Jahre von Herbert Becelas Amtszeit fiel nicht nur der Aufbau des Botanischen Gartens am neuen Standort, sondern auch die tiefgreifende Umstrukturierung der Universität. Unmittelbare Auswirkung auf den Botanischen Garten hatte dies durch den Wegfall eines dauerhaft den Garten und Institut leitenden Professors („Ordinarius“), der durch den regelmäßig meist im Jahresturnus - wechselnden „Geschäftsführenden Direktor" ersetzt wurde. Einen am Garten arbeitenden wissenschaftlichen Leiter oder Kustos, wie für Botanische Gärten sinnvoll und üblich, gab es nicht. Damit kam Herbert Becela eine besonders 
wichtige Rolle für die Entwicklung und Erhaltung des Gartens zu. Zum Ende seiner Amtszeit hin brachte die räumliche Neuordnung der Goethe-Universität wiederum wichtige Einschnitte: Die Verlagerung der Biologischen Institute an den Naturwissenschaftlichen Campus am Stadtrand in Niederursel begann ebenso wie die Planung eines neuen Botanischen Gartens dort. Damit einher gingen auch durchaus kontroverse Überlegungen über die Zukunft „seines“ Botanischen Gartens, zu denen auch Umnutzung des Geländes und Bebauung gehörten. Sicherlich war es für Herbert Becela eine große Freude und Erleichterung, als - lange nach seinem Ausscheiden aus dem aktiven Dienst - mit der Angliederung an den Palmengarten der Stadt Frankfurt 2012 die Zukunft des Botanischen Gartens gesichert werden konnte. Bis heute sind große Teile des Gartens in seiner ursprünglichen Konzeption und Bepflanzung erhalten.

Herbert Becela wurde am 16. April 1927 in Waldniel/Niederrhein geboren. Nach dem Kriegsdienst als Flakhelfer, Soldat und dann kurzer Kriegsgefangenschaft legte er 1946 das Abitur ab. Seine ursprüngliche Absicht, Tiermedizin zu studieren, konnte er aus wirtschaftlichen Gründen nicht realisieren. Nach einer Dolmetscher-Tätigkeit bei der amerikanischen Militärregierung folgte von 1948 bis 1950 eine Gärtnerlehre, damals zusammen mit Praxiszeiten die Voraussetzung für ein Studium an der Lehr- und Forschungsanstalt in Geisenheim. Nach der ersten gärtnerischen Anstellung in Wiesbaden ergab sich 1951 bis 1952 eine einjährige Beschäftigung als „Wechselstellengärtner“ im Palmengarten Frankfurt unter dem damaligen Direktor Fritz Encke (erst am 3. Mai 1948 war der Palmengarten wieder für deutsche Besucher geöffnet worden, bis dahin war er seit Kriegsende den amerikanischen Streitkräften vorbehalten). Der Austausch von Fachkräften zwischen Botanischen Gärten war zu dieser Zeit gängige Praxis, in der Regel für ein Jahr besetzte sogenannte "Wechselstellen“ ermöglichten Gärtnern das Sammeln von Erfahrung in verschiedenen Gärten und Kulturbereichen. $\mathrm{Zu}$ dieser Zeit wurde wohl der Grundstein ge- legt für die enge gärtnerische Zusammenarbeit und das gute Verhältnis zwischen Palmengarten und Botanischem Garten während Becelas gesamter Dienstzeit.

Nach erneuter Tätigkeit in einem Erwerbsbetrieb in Bad Homburg folgte die Anstellung als Reviergärtner für Warmhauskulturen am Botanischen Garten Marburg (1953 bis 1956). Danach konnte er das Studium an der Lehrund Forschungsanstalt Geisenheim beginnen (Fachrichtung Blumen- und Zierpflanzenbau). Nach dem Abschluss 1958 als staatlich diplomierter Gartenbauinspektor, später DiplomIngenieur, schloss sich zunächst die Anstellung als Gartenbautechniker am Botanischen Garten Mainz und am 1. August 1958 der Wechsel zum Botanischen Garten Frankfurt an. Nach dem Ausscheiden des damaligen Technischen Leiters, Gartenoberinspektor KuRT Kienne (31. Juli 1961), wurde Becela sein Nachfolger, zunächst als Garteninspektor, später als Technischer Amtsrat. In diese Zeit fallen auch die Eheschließung mit Katherina Becela, geb. Sprenger (1961) und die Geburt der Tochter Christine (1963).

Am 31. Oktober 1992, wenige Monate nach seinem 40-jährigen Dienstjubiläum, ging BeCELA in den wohlverdienten Ruhestand. Am 1. Januar 1993 trat sein Nachfolger Manfred Wessel den Dienst an.

Herbert Becelas besonderes botanisches Interesse galt der naturgetreuen Erhaltung der anspruchsvollen und arbeitsintensiven, nach pflanzensoziologischen Vorgaben gestalteten Reviere, Spezialkulturen wie z. B. den Rhodondendren oder dem Alpinum und auch der Gestaltung der Gartenanlagen des Gästehauses der Universität in Riezlern in den Allgäuer Alpen. Ein wichtiges Anliegen war ihm auch die vollständige und stets aktuelle Etikettierung der Pflanzen als einer Kernaufgabe Botanischer Gärten. Ihm und seinen Mitarbeitern ist es zu verdanken, dass der Botanische Garten über 30 Jahre hinweg den hohen Standard in der Pflanzenkultur und die arbeitsintensiven Reviere erhalten konnte, die auch heute noch Charakteristikum des Gartens sind. Am 30. Juli 2016 ist Herbert Becela in Eschborn gestorben. 